\title{
Dynamic Behavior and Constitutive Relationship of Mudstone Slip Zone of Landslide with Weak Interlayer
}

\author{
Jingjing Zhou $\mathbb{D D}^{1}{ }^{1}$ Fasuo Zhao $\mathbb{D}^{1},{ }^{1}$ Yanbo Zhu $\mathbb{D}^{1},{ }^{1}$ Wenqi Dong $\mathbb{D}^{1},{ }^{1}$ and Ziguang He ${ }^{2}$ \\ ${ }^{1}$ College of Geological Engineering and Geomatics, Chang'an University, Xi'an, Shaanxi 710064, China \\ ${ }^{2}$ Huanghuai University, Institute of Architecture Engineering, Zhumadian, Henan 463000, China \\ Correspondence should be addressed to Yanbo Zhu; zhuyanbo@chd.edu.cn
}

Received 13 April 2021; Revised 22 July 2021; Accepted 18 August 2021; Published 27 August 2021

Academic Editor: Pengfei Wang

Copyright ( 2021 Jingjing Zhou et al. This is an open access article distributed under the Creative Commons Attribution License, which permits unrestricted use, distribution, and reproduction in any medium, provided the original work is properly cited.

Sliding zone dynamics in the Qinling-Daba mountain area under different dynamic parameters have not been studied extensively. In this study, we investigated the dynamic behavior of the sliding zones of a high-steep rock landslide in the Qinling-Daba mountain area under the influence of dynamic stress amplitude and frequency and proposed an empirical model of the dynamic constitutive relationship. The dynamic behavior was studied based on a cyclic triaxial test system. The results indicated that an increase in the dynamic stress amplitude decreased the dynamic elastic modulus linearly, increased the damping ratio, and increased the axial strain exponentially. Among these properties, the elastic strain was found to be more sensitive to the increase in the dynamic stress amplitude than the plastic strain. As the loading frequency increased, the dynamic elastic modulus increased, whereas the damping ratio decreased. Furthermore, the proposed empirical model of the dynamic constitutive relationship between the vibration number and loading frequency based on the dynamic elastic modulus could satisfactorily describe the dynamic stress-strain relationships of the samples from test stability and failure zones. These findings are expected to make a significant contribution toward further revealing the sliding mechanism of such landslides.

\section{Introduction}

Landslides frequently occur in the Qinling-Daba mountain area, which is located south of the Shaanxi Province and north of the Sichuan Province in China. This is subjected to its unique environmental conditions and human activities $[1,2]$. The Qinling-Daba mountain area is characterized by steep topography, various strata and lithology, and soft rocks and joints (structural planes). Moreover, it has strong regional tectonic activity, resulting in frequent earthquakes. Additionally, its slopes are disturbed by drilling, blasting, mechanical excavation, and other dynamic loads caused by mining, road construction, and other engineering activities. These factors promote the occurrence of geological disasters, such as landslides. Landslides caused by vibrations can result in severe property damage and casualties [3-6]. For instance, on August 12, 2015, a $168 \times 10^{4} \mathrm{~m}^{3}$ slope failure occurred in Shanyang County, Shaanxi Province, China, resulting in 65 deaths and an economic loss of 500 million yuan [7].
Therefore, it is necessary to study the dynamic deformation characteristics of the sliding zones of a landslide to identify the underlying mechanism.

In recent years, there have been an increasing number of studies on the dynamic deformation characteristics of rocks and soil [8-11]. Anupam et al. [12] used fly ash and rice husk ash to investigate the deformation behavior of subgrade soil mixtures under repeated triaxial loading. Mu et al. [13] analyzed the influence of different dynamic stresses and confining pressures on the cumulative deformation law of red clay in subgrade engineering to determine the critical dynamic stress range under a low confining pressure. Wichtmann et al. [14] studied the effects of strain amplitude, average stress, and the number of load cycles on the accumulation rate by conducting numerous drained cyclic tests under triaxial extension. Touqan et al. [15] conducted consolidated drained cyclic triaxial tests to simulate the long-term response of a fouled railway substructure under progressive repetitive loading and unloading cycles. Zhuang et al. $[16,17]$ conducted a series of dynamic triaxial tests on 
expansive soils in foundation engineering using a GDS and found that the dynamic modulus of elasticity increased and the damping ratio decreased the increase in the confining pressure and consolidation stress ratio. By studying the plastic deformation behavior of the fine-grained soils under intermittent cyclic loading, Nie et al. [18] found that intermittent loading could significantly retard the development of plastic strain. Yoshinaka et al. [19] performed cyclic triaxial tests on four saturated Miocene soft rocks from Japan to study the deformation behavior, pore pressure variation, strength mobilization, and contraction/dilation characteristics. Zhang et al. [20, 21] conducted cyclic triaxial tests on loess and weathered red mudstone to obtain the stress-strain characteristics of undisturbed soil under repeated loading. In addition, Rabczuk and Ren $[22,23]$ proposed some numerical methods to study the crack distribution mode of materials under dynamic action, thereby providing a basis for research on the cumulative damage of different materials during dynamics. Vu-Bac et al. [24] provided a toolbox for sensitivity analysis to quantify uncertain input parameters in such numerical studies. The abovementioned studies highlight the need for investigating the dynamic characteristics of rocks and soils in the subgrade, foundation, and other civil engineering projects. Concurrently, findings have been reported on the influence of landslides under vibration [25]. Zhu et al. [26, 27] conducted a detailed field investigation and a series of dynamic triaxial tests to examine the dynamic characteristics of different staggered zones in the sliding belts of the Daguangbao landslide. They found that the dynamic elastic modulus and damping ratio were significantly affected by the material composition. Xu et al. [28] found that under seismic loading, intercalations rapidly caused greater cumulative deformation and fatigue damage than those of a surrounding rock mass. Song et al. [29] examined the influence of water content on the dynamic characteristics of a sliding zone using dynamic triaxial tests. However, the abovementioned studies are focused on the dynamic characteristics of sliding zones with different materials, moisture contents, and structural plane angles. There are relatively fewer studies on the deformation characteristics of a sliding zone in the weak interlayer of a landslide under cyclic dynamic loads with varying stress amplitudes and frequencies. Therefore, it is necessary to conduct relevant investigations in this regard.

In this study, the authors conducted a series of cyclic dynamic loading tests using a GDS dynamic triaxial instrument to study the effects of the dynamic stress amplitude and frequency on the dynamic deformation characteristics of a sliding zone of the Shanyang landslide in Shaanxi Province, China. In addition, this study established a dynamic constitutive model of the dynamic stress-strain relationship of a sample under cyclic loading, based on the dynamic elastic modulus.

\section{Test Materials and Scheme}

2.1. Test Materials and Equipment. The test materials were obtained from the Shanyang landslide in Shaanxi Province in China (see Figure 1). The Shanyang landslide that occurred at 0:30 a.m. on August 12, 2015 (Beijing, UTC+8) was caused by rainfall and long-term vibration, among other conditions. The landslide was approximately $550 \mathrm{~m}$ in length, $130 \mathrm{~m}$ in width, $10-40 \mathrm{~m}$ in thickness, and $168 \times 10^{4} \mathrm{~m}^{3}$ in volume. The slope lies on the southeast wing of the Yaolinghe anticline with inverted strata and slope angles ranging from $42^{\circ}$ to $55^{\circ}$, controlled by three sets of regional structural planes. The steep slope consists of thick dolomite from the middle Sinian Dengying group and overlies the interbedding of carbonaceous claystone and siliceous rocks from the lower Cambrian Shuigoukou group. The two sets of strata have an unconformity contact. Additionally, there are weak intercalations in the unconformity contact, mainly mudstone, which has a strong water-holding capacity. However, when the mudstone comes into contact with water, its strength abruptly decreases.

In addition, there are frequent mining activities in the landslide area. Owing to the short vertical distance between the mining roadway and weak interlayer zone $(21 \sim 35 \mathrm{~m})$, the Shanyang slope is continuously affected by vibrations. To understand the sliding mechanism and study the influence of vibrations on the stability of landslides, mudstone samples from the weak intercalation layer were selected to perform a series of dynamic triaxial cyclic loading tests.

Table 1 lists the physical and mechanical properties of the samples. In Table 1, $\rho$ denotes the dry density, $\omega$ denotes the natural moisture content, $W_{L}$ denotes the liquid limit, $W_{P}$ denotes the plastic limit, $I_{P}$ denotes the plastic index, $c$ denotes the cohesion, and $\varphi$ denotes the internal friction angle. Remolded samples were selected because of the difficulty in obtaining undisturbed mudstone. The samples were prepared based on their natural moisture content and dry density. The diameter and height of each sample were $38 \mathrm{~mm}$ and $80 \mathrm{~mm}$, respectively.

The dynamic triaxial tests were conducted using a GDS dynamic triaxial testing system (DYNTTS) which comprises a main machine, a universal triaxial cell top, deairing block, pore pressure transducers, a GDS standard controller, and data acquisition units (see Figure 2). The detailed parameters of the GDS/DYNTTS are as follows: vertical vibration frequency of $0.01-5 \mathrm{~Hz}$, the static or dynamic axial load of $0-40 \mathrm{kN}$, and confining pressure of $0-2000 \mathrm{kPa}$.

2.2. Test Scheme. Based on the Chinese National Specification (Standard for Geotechnical Testing Method, GB/T 50123-2019) [30], the dynamic loads applied in this test were repeated cyclic loads. The applied dynamic loads were sinusoidal vibration waves, and the confining pressure was $400 \mathrm{kPa}$.

First, a sample was placed in a saturator for air extraction. Subsequently, the sample was transferred to a sleeve containing a rubber diaphragm and installed on the base of the GDS apparatus to saturate for $24 \mathrm{~h}$. When the $B$ value of the specimen exceeded 0.98 , the specimen was isotropically consolidated under a certain effective confining pressure. Once the water discharge was below $0.1 \mathrm{~cm}^{3} / \mathrm{h}$, the consolidation was considered to be completed. Finally, cyclic loading triaxial tests were performed under undrained conditions, and the dynamic loads were applied in stages. Vibrations were introduced 10 times at each dynamic 


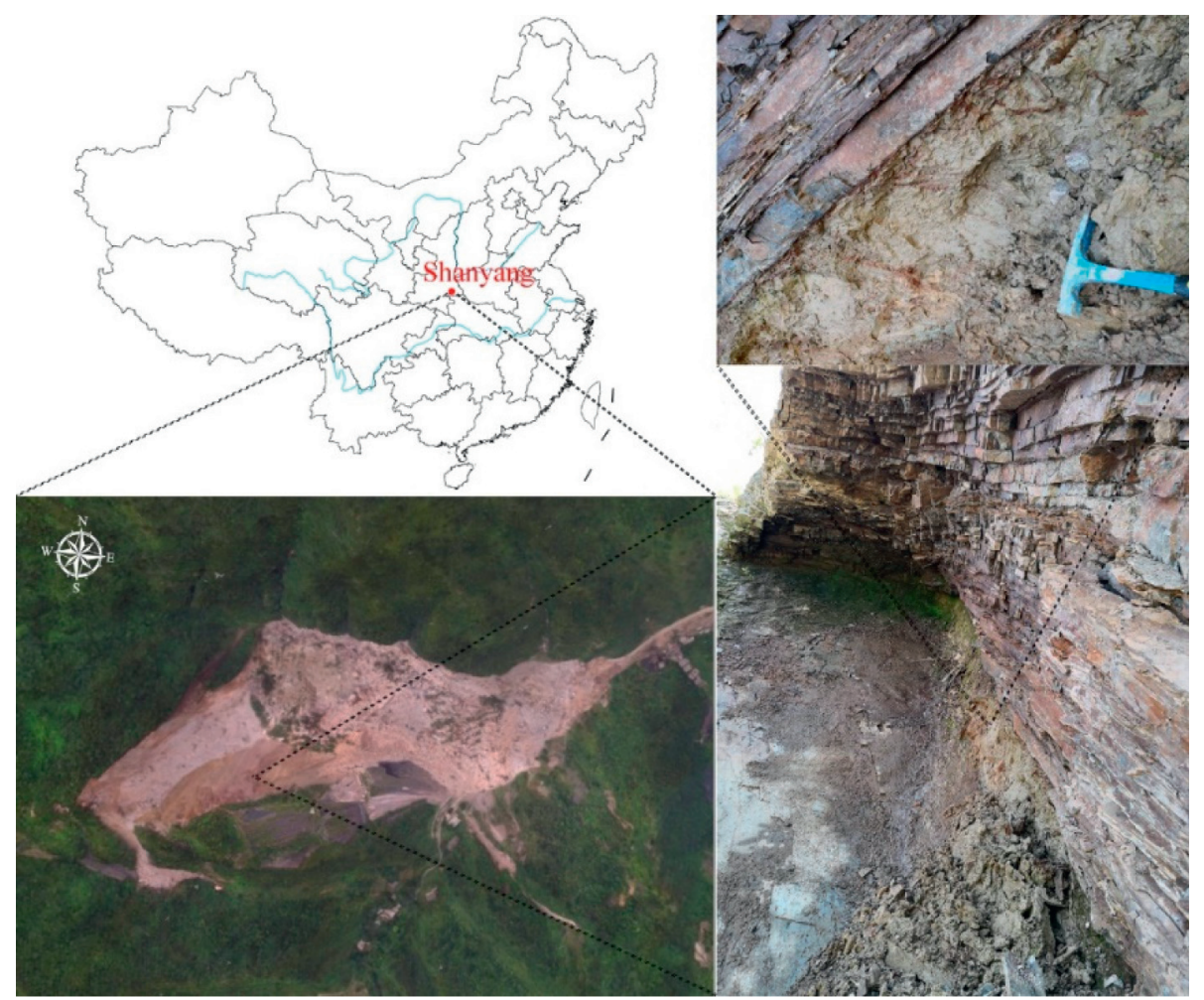

Figure 1: Sampling location map.

TABLE 1: Index properties of tested samples.

\begin{tabular}{lcccccc}
\hline$\rho\left(\mathrm{g} / \mathrm{cm}^{3}\right)$ & $\omega(\%)$ & $W_{L}$ & $W_{P}$ & $I_{P}$ & $C(\mathrm{kPa})$ & $\varphi\left(^{\circ}\right)$ \\
\hline 1.60 & 30.28 & 39.22 & 24.46 & 14.76 & 51.30 & 16.75 \\
\hline
\end{tabular}

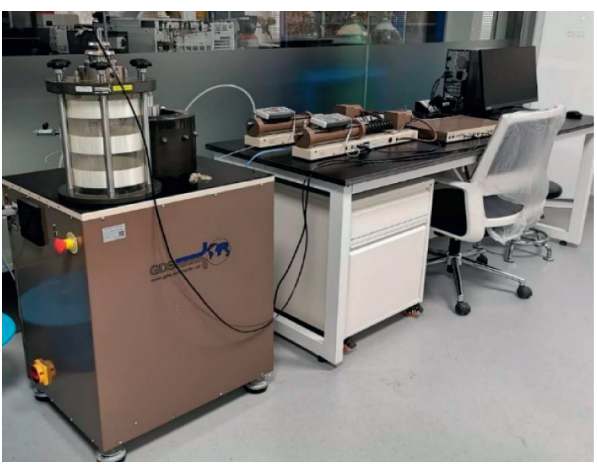

Figure 2: GDS/DYNTTS.

loading stage. The dynamic stress amplitude and frequency were considered in this test. Table 2 lists the test scheme details, and Figure 3 illustrates the loading path of the test stress.

\section{Results and Analysis}

3.1. Axial Strain. The axial strain time history curve (frequency of $0.5 \mathrm{~Hz}$ ) is illustrated in Figure 4. With the increase in time, the axial strain fluctuated with the loading waveform and demonstrated an increasing trend overall. In the early stage, the growth rate of the axial strain was low under the vibration load with a small amplitude of the dynamic stress. At a later stage, with the increase in the dynamic stress amplitude, the growth rate of the axial strain increased gradually. When the dynamic stress amplitude exceeded a certain threshold, the axial strain increased rapidly, and the specimen was destroyed. The axial strain of the specimen under cyclic loading comprised elastic and plastic strains. The lowest point in the axial strain curve of a sample is its cumulative plastic strain, and the difference between the highest and lowest points represents the elastic strain. In Figure $4, \varepsilon_{r}$ represents the elastic strain and $\varepsilon_{p}$ denotes the plastic strain. The variation curves of the elastic and plastic strains with a vibration time of $0.5 \mathrm{~Hz}$ are depicted in Figure 5.

As depicted in Figure 5, before the failure of the specimen, the elastic and plastic strains increased with the increase in cycle number. Their trends were consistent with those of the total axial strain. Under small-amplitude loading, the strains increased gradually. With the increase in the cycle number and amplitude, the strain growth rate increased rapidly. The elastic deformation was more rapid than the plastic deformation in the early stage of loading. With the increase in the dynamic stress amplitude and cycle number, the deformation of the specimen transitioned from the elastic to plastic deformation stage, and the plastic strain rate increased more rapidly than the elastic strain rate. Additionally, the elastic strain curve exhibited a clear climbing phenomenon, whereas the plastic strain curve was relatively smooth. Specifically, the elastic strain increased sharply when the dynamic stress amplitude increased at each stage, whereas the plastic strain did not. Therefore, the elastic strain was more sensitive to the increase in the dynamic stress 
TABLE 2: Dynamic loading test scheme of mudstone sample.

\begin{tabular}{lccc}
\hline Group & Confining pressure $(\mathrm{kPa})$ & Frequency $(\mathrm{Hz})$ & Dynamic stress amplitude \\
\hline 1 & 400 & 0.5 & Initial value $\sigma_{d}=5 \mathrm{kPa}$, increased by $10 \mathrm{kPa}$ \\
2 & 400 & 1 & Initial value $\sigma_{d}=5 \mathrm{kPa}$, increased by $10 \mathrm{kPa}$ \\
3 & 400 & 3 & Initial value $\sigma_{d}=5 \mathrm{kPa}$, increased by $10 \mathrm{kPa}$ \\
\hline
\end{tabular}

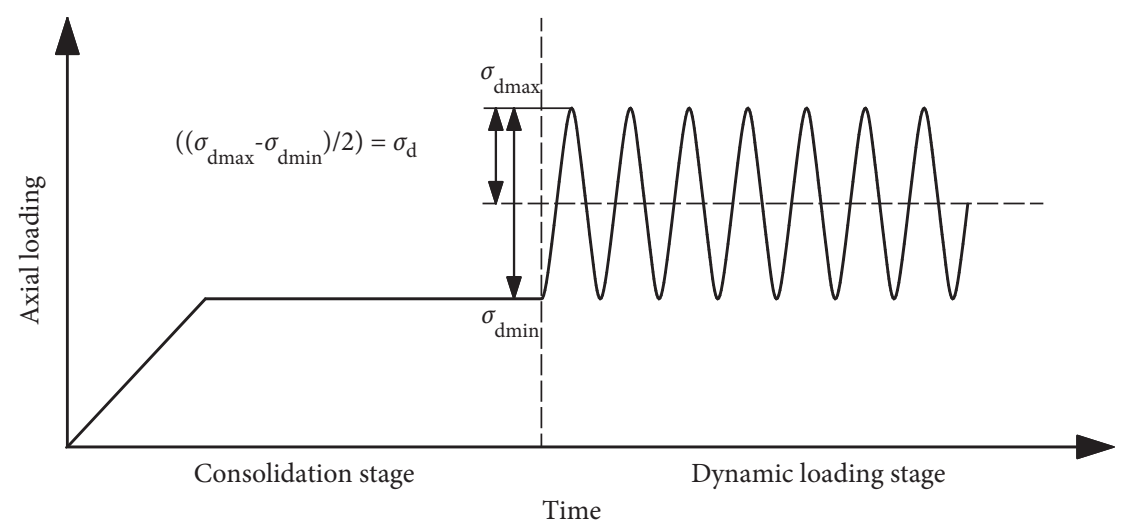

Figure 3: Schematic of triaxial cyclic loading. Note that $\sigma_{d \max }$ denotes the maximum dynamic stress, $\sigma_{d \min }$ denotes the minimum dynamic stress, and $\sigma_{d}$ denotes the dynamic amplitude.

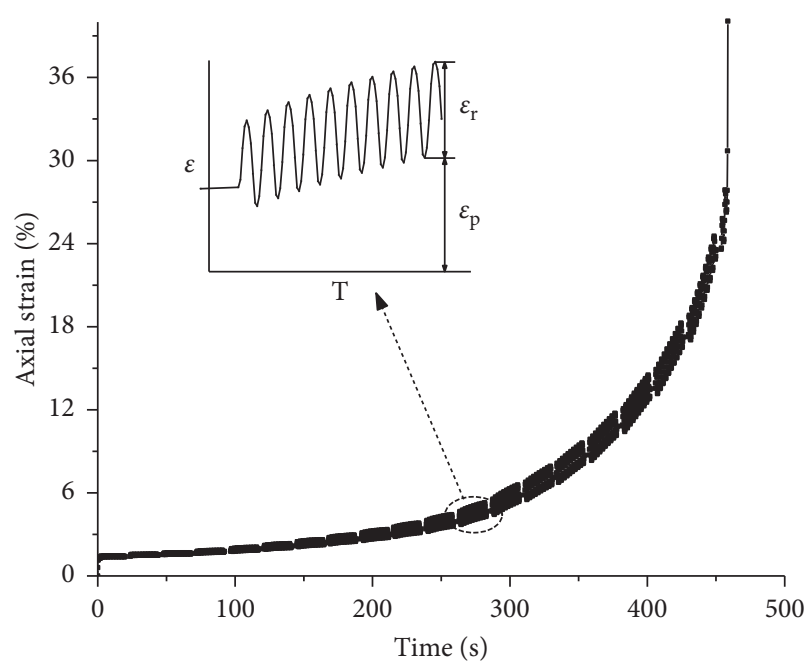

FIgURE 4: Time history curves of axial strain at $0.5 \mathrm{~Hz}$.

amplitude than the plastic strain under dynamic load applications.

Figure 6 depicts a comparison of the elastic and plastic strains at different frequencies. The changing trends of both strains were similar under different frequencies. As the frequency increased, the number of cycles needed for the failure of the specimen increased, and the small strain when the specimen was damaged implied a low strain growth rate. The influence of the frequency on the strains was more significant at low frequencies than that at high frequencies, and the influence of the frequency decreased as the frequency increased.

Studies [31, 32] have found that cumulative plastic strain versus cycle number curves under cyclic dynamic loading can be classified into three types, namely, stable, critical, and

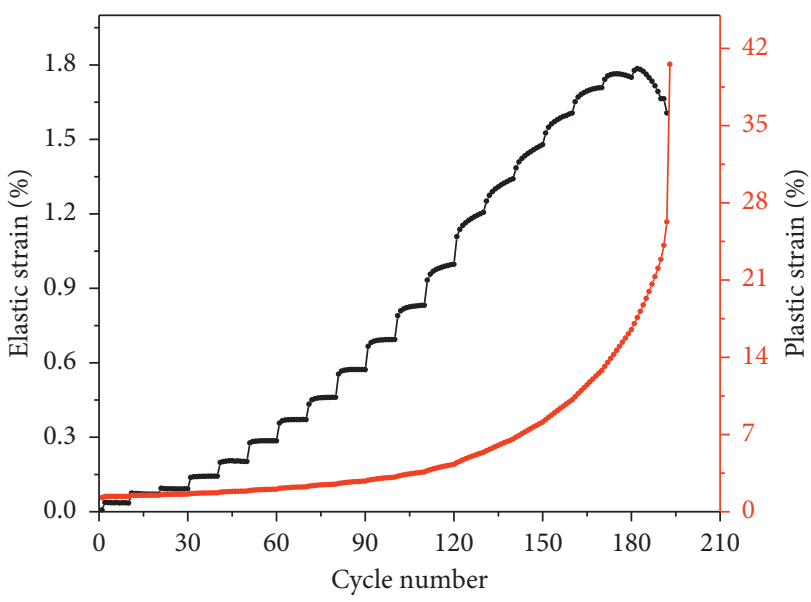

FIgURE 5: Curves of elastic and plastic strains at $0.5 \mathrm{~Hz}$.

failure. The corresponding curves with the dynamic stress amplitudes under different frequencies obtained in this study are illustrated in Figure 7.

As depicted in Figure 7, the increase in the dynamic stress amplitude and cycle number increased the plastic strain rate, and the curves approached the $y$-axis. The dynamic stress amplitude and loading frequency significantly affected the plastic strain curve. When the loading frequencies were $0.5,1$, and $3 \mathrm{~Hz}$, the transition values of the dynamic stress amplitudes from the stable zone to the critical zone were 125,235 , and $245 \mathrm{kPa}$, respectively. The corresponding transition values from the critical zone to the failure zone were 155,275 , and $305 \mathrm{kPa}$, respectively.

Based on the previous research studies [13, 31-34], equations (1)-(3) express the curves of the cumulative plastic strain versus the cycle number in the stable, critical, and failure zones, respectively. 


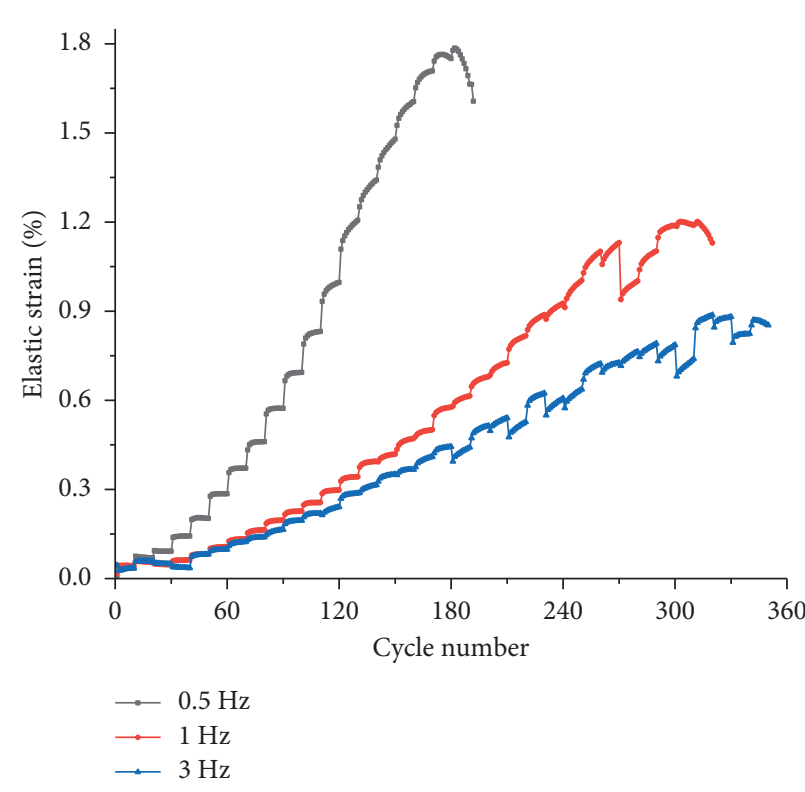

(a)

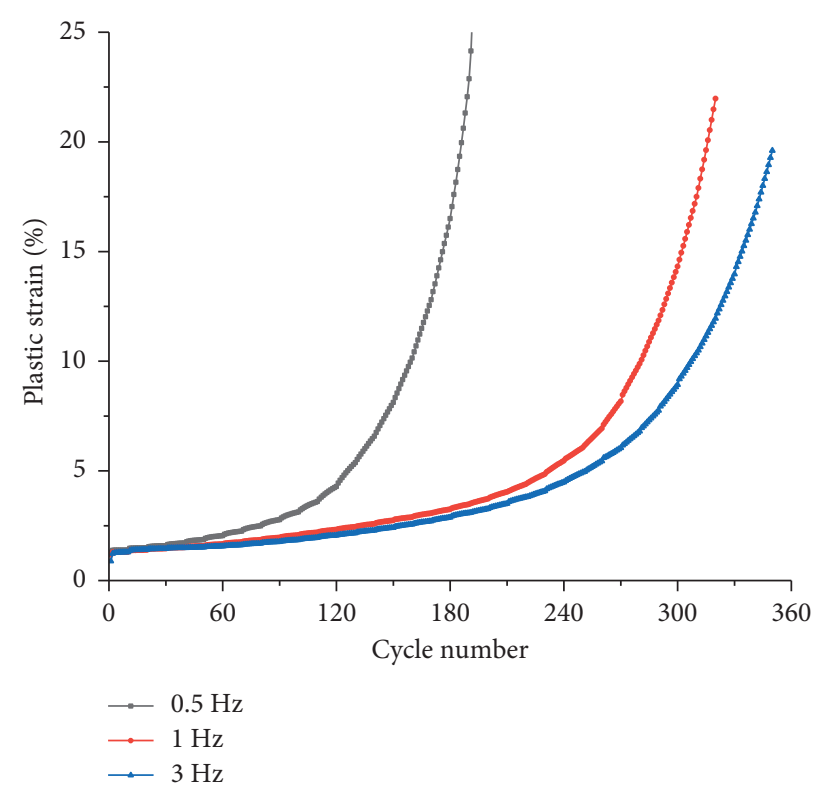

(b)

Figure 6: Elastic and plastic strain curves at different frequencies. (a) Elastic strain. (b) Plastic strain.

$$
\begin{aligned}
& \varepsilon_{p}=a(1+b \lg N), \\
& \varepsilon_{p}=A N+B, \\
& \varepsilon_{p}=c N^{d} .
\end{aligned}
$$

Here, $\varepsilon_{p}$ denotes the plastic strain, $n$ denotes the cycle number, and $a, b, A, B, c$, and $d$ represent the parameters related to the dynamic stress and soil properties.

In this study, (1)-(3) were used to fit the cumulative plastic strain curves at $0.5 \mathrm{~Hz}$. When the dynamic stress amplitude is varied from $75 \mathrm{kPa}$ to $115 \mathrm{kPa}$, the curve type is stable, and it can be fitted by equation (1). When the dynamic stress amplitude ranges from $125 \mathrm{kPa}$ to $145 \mathrm{kPa}$, the curve type is critical, and it can be fitted by equation (2). When the dynamic stress amplitude varies from $155 \mathrm{kPa}$ to $185 \mathrm{kPa}$, the curve type is a failure, and it can be fitted by equation (3).

The fitting parameters are listed in Table 3, which vary under different dynamic stress amplitudes because the fitting parameters are related to the applied dynamic stress amplitudes. Equations (1)-(3) have good applicability to the test data of the stable, critical, and failure curves, and the correlation coefficients are above 0.90 . The fitting effect is ideal, which indicates that the relationship between the cumulative strain and the number of cyclic vibrations under cyclic loading can be described appropriately.

3.2. Dynamic Stress-Strain Relationship. The curves of the deviator stress versus the axial strain of the samples at different frequencies are illustrated in Figure 8.

As depicted in Figure 8, when the strain was less than $3.5 \%$, the dynamic stress increased sharply, following which as the axial strain increased, the dynamic stress first increased gradually, subsequently tended to be stable, and finally began to decrease after reaching the peak value.

At the start of the test, the sample with intact structure and the small strain was in the elastic deformation stage, where the stress-strain curves under different frequencies were similar. As the increase of dynamic stress amplitude, the structure is gradually damaged along with slip between internal particles. In this process, the strain developed faster, shear failure gradually formed; deviator stress decreased. Meanwhile, it can be found that the greater the loading frequency is, the greater the dynamic stress is needed for the specimen reaches the same strain value. The results indicate that the increase in the frequency can restrain the development of the dynamic strain of the mudstone samples and benefit the stability of the landslide.

3.3. Dynamic Elastic Modulus. The dynamic elastic modulus, $E_{d}$, is determined as the slope of the line connecting the two ends of the hysteresis loop in the dynamic stress-strain curve:

$$
E_{d}=\frac{\sigma_{d \max }-\sigma_{d \min }}{\varepsilon_{d \max }-\varepsilon_{d \min }},
$$

where $\sigma_{d \max }$ and $\sigma_{d \min }$ denote the maximum and minimum dynamic stresses in a single loading cycle, respectively, and $\varepsilon_{d \max }$ and $\varepsilon_{d \min }$ represent the maximum and minimum dynamic strains in a single loading cycle, respectively.

The $E_{d}-\sigma_{d}$ obtained from the dynamic elastic modulus of the fifth cyclic loading under each loading level and the corresponding dynamic stress amplitude are depicted in Figure 9.

Figure 9 shows that the dynamic elastic modulus of the mudstone decreases almost linearly with the increase in the 


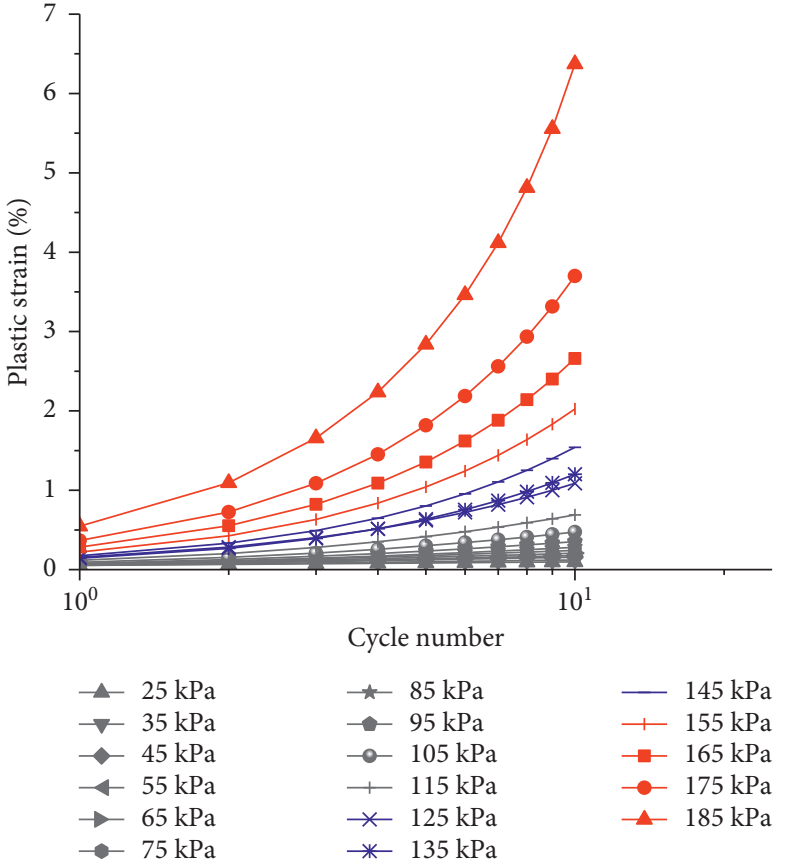

(a)

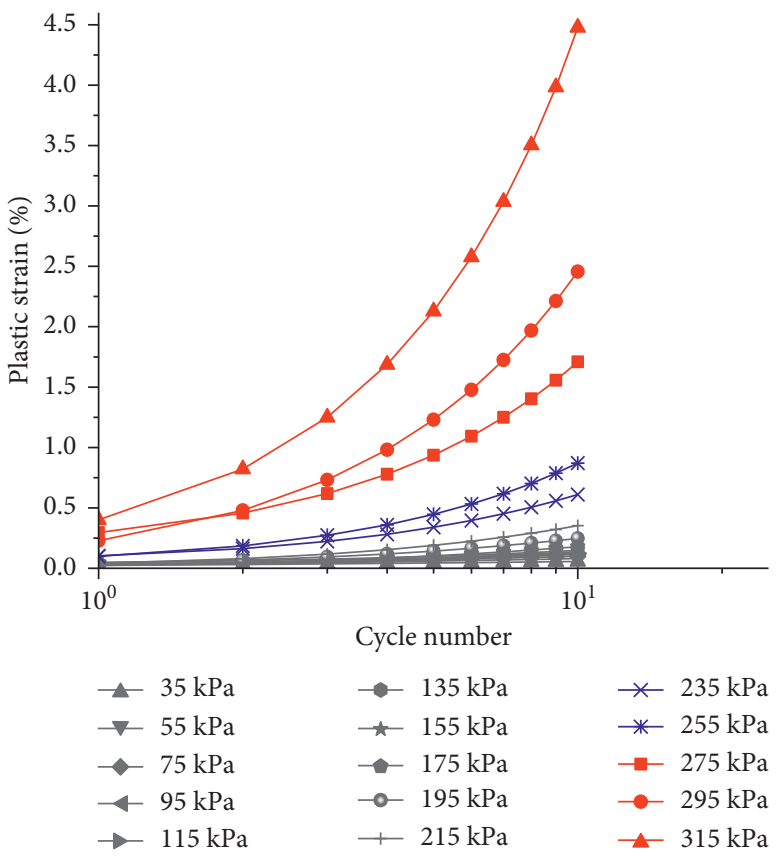

(b)

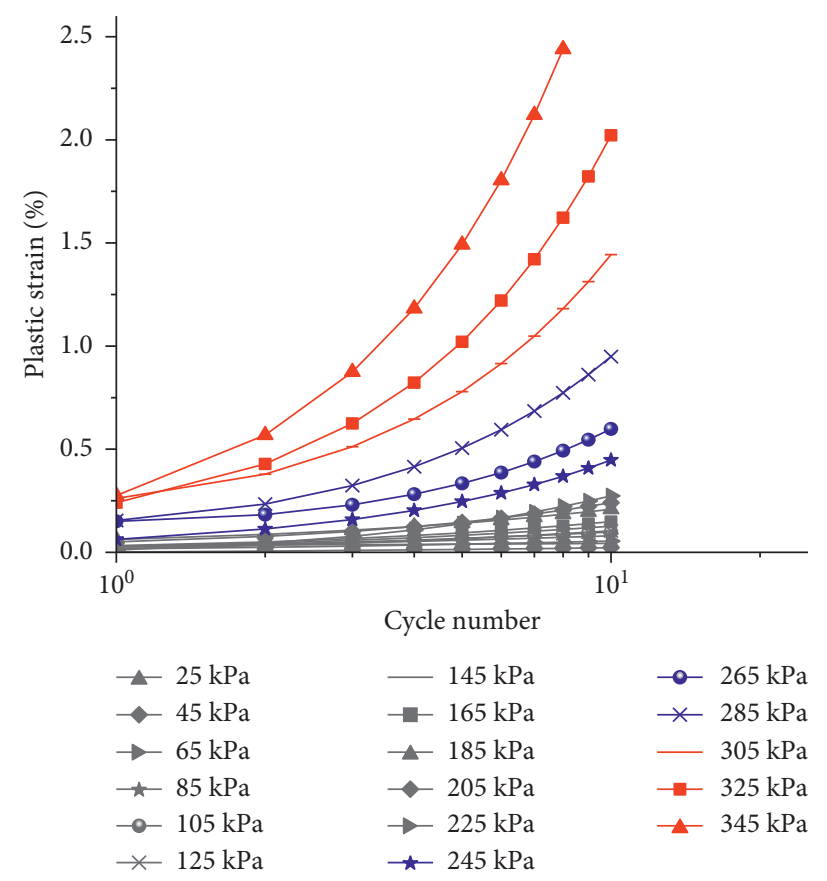

(c)

Figure 7: Curves of cumulative plastic strain versus cycle number for different frequencies. (a) $0.5 \mathrm{~Hz}$. (b) $1 \mathrm{~Hz}$. (c) $3 \mathrm{~Hz}$.

dynamic stress amplitude. A small frequency implies a rapid linear decrease in the dynamic elastic modulus. For the same dynamic stress amplitude, it can be observed from Figure 8 that a large loading frequency implies a large dynamic elastic modulus. The reason is that under a constant amplitude cyclic load, the higher the frequency, the faster the dynamic loading rate, and the axial deformation is too late to produce. From a microscopic perspective, the instantaneous deformation is small, whereas from the macroscopic perspective, the dynamic elastic modulus increases with the increase in frequency [17].

Additionally, this study analyzed the change in the dynamic elastic modulus with the cycle number. Consider the $E_{d}-N$ curve (see Figure 10) at a frequency of $1 \mathrm{~Hz}$ as an example. The dynamic elastic modulus of the sample increased with the increase in the number of cycles under a small dynamic stress amplitude. When the dynamic stress amplitude increased, the rate of increase of the dynamic 
TABLE 3: Fitting of cumulative deformation curve with a frequency of $0.5 \mathrm{~Hz}$.

\begin{tabular}{|c|c|c|c|c|}
\hline Dynamic stress amplitude $(\mathrm{kPa})$ & \multicolumn{2}{|c|}{ Fitting parameter } & $R^{2}$ & Curve type \\
\hline 75 & $a=0.0609$ & $b=2.84697$ & 0.98048 & \multirow{5}{*}{ Stable } \\
\hline 85 & $a=0.05071$ & $b=4.27911$ & 0.98918 & \\
\hline 95 & $a=0.05085$ & $b=5.53616$ & 0.99279 & \\
\hline 105 & $a=0.04962$ & $b=7.86$ & 0.99598 & \\
\hline 115 & $a=0.0447$ & $b=13.12821$ & 0.99838 & \\
\hline 125 & $A=0.08505$ & $B=0.10293$ & 0.99816 & \multirow{3}{*}{ Critical } \\
\hline 135 & $A=0.03743$ & $B=0.11785$ & 0.9997 & \\
\hline 145 & $A=0.03293$ & $B=0.15219$ & 0.99984 & \\
\hline 155 & $c=0.22034$ & $d=0.96399$ & 0.97206 & \multirow{4}{*}{ Failure } \\
\hline 165 & $c=0.28239$ & $d=0.9741$ & 0.97248 & \\
\hline 175 & $c=0.3545$ & $d=1.01739$ & 0.97419 & \\
\hline 185 & $c=0.4654$ & $d=1.12909$ & 0.97795 & \\
\hline
\end{tabular}

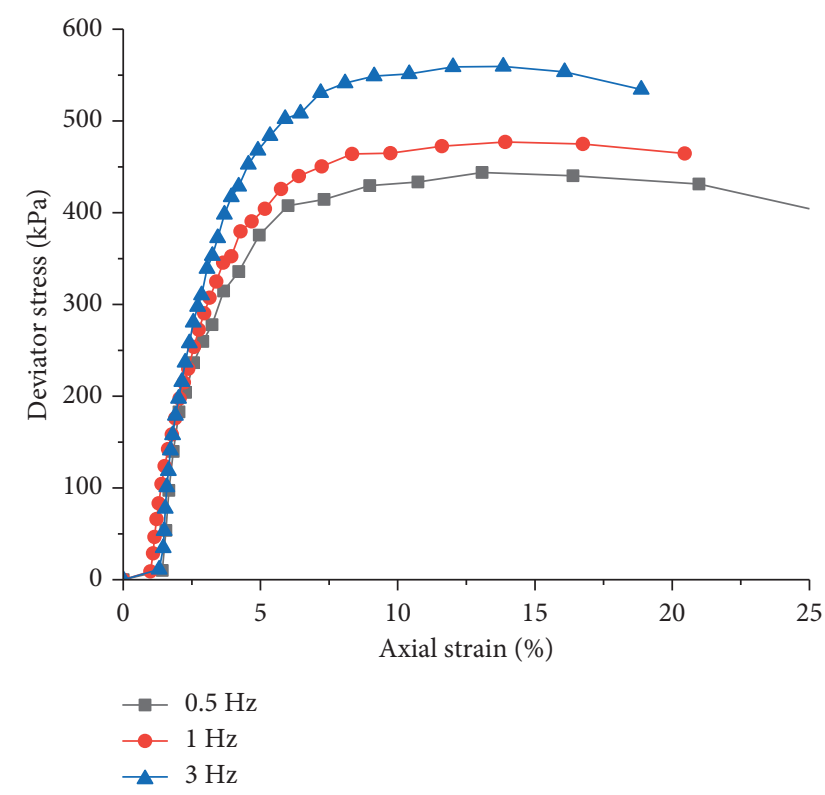

FIgURE 8: Stress-strain curves at different frequencies.

elastic modulus began to decrease with the number of cycles until the increase rate reached zero. Subsequently, as the dynamic stress amplitude continued to increase, the dynamic elastic modulus began to decrease with the number of cycles, and the decrease rate continued to increase.

3.4. Damping Ratio. The damping effect of soil on the dynamic load manifests the lag phenomenon of the strain in the hysteresis loop under cyclic loading, which is mainly caused by the internal friction effect of the relative sliding between particles. The damping ratio, $\lambda$, which is determined by the shape of the hysteresis loop, can reflect the ability of the soil to absorb vibration energy [35].

$$
\lambda=\frac{1}{4 \pi} \frac{A_{0}}{A_{T}},
$$

where $A_{0}$ represents the mechanical energy consumed by the soil during the loading and unloading periods and $A_{T}$

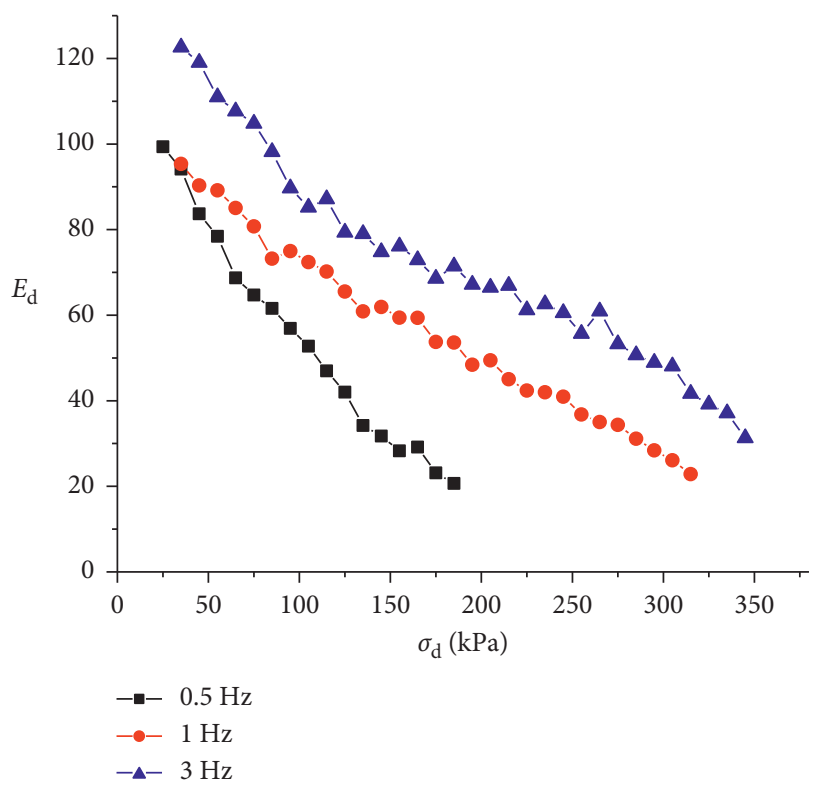

FIGURE 9: Curves of dynamic elastic modulus versus dynamic stress amplitude at different frequencies.

denotes the maximum elastic energy obtained by the soil in a cycle.

The $\lambda-\sigma_{d}$ curves plotted using the damping ratio of the fifth cyclic loading under each loading level and the corresponding dynamic stress amplitude are depicted in Figure 11.

Figure 11 shows that the damping ratio of the mudstone sample increases with the increase in the dynamic stress amplitude. Under small dynamic stress amplitudes, the damping ratio increased linearly. Subsequently, with the increase in the dynamic stress amplitude, the increase rate of the damping ratio decreased and tended to be stable.

Under the same dynamic stress amplitude, the higher frequency leads to a faster loading rate. Thus, there is insufficient time for the mudstone sample to produce large deformation, thereby reducing the energy consumption. Therefore, the larger the final deformation, the higher the energy consumption, and the greater the damping ratio, and vice versa. 


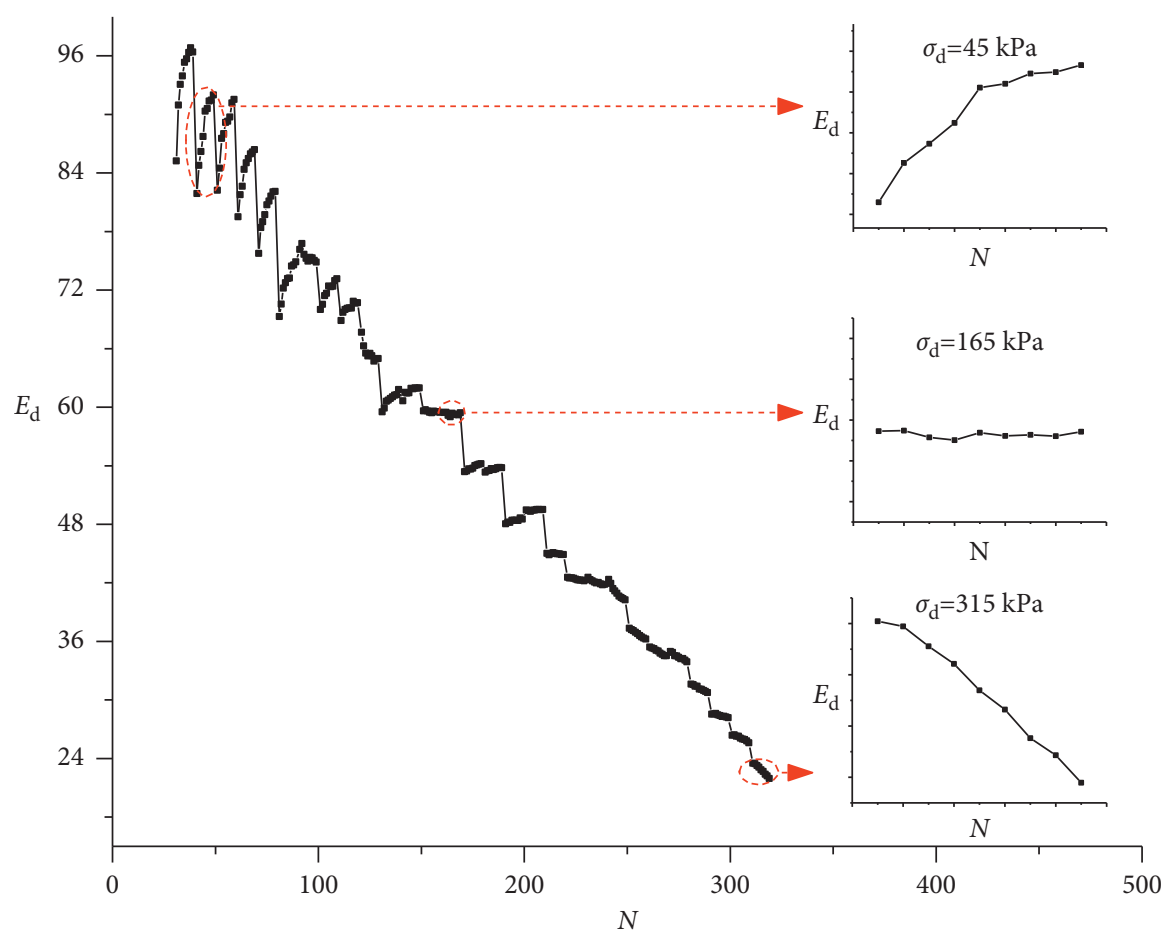

Figure 10: Dynamic elastic modulus versus cycle number curves under different dynamic stress amplitudes.

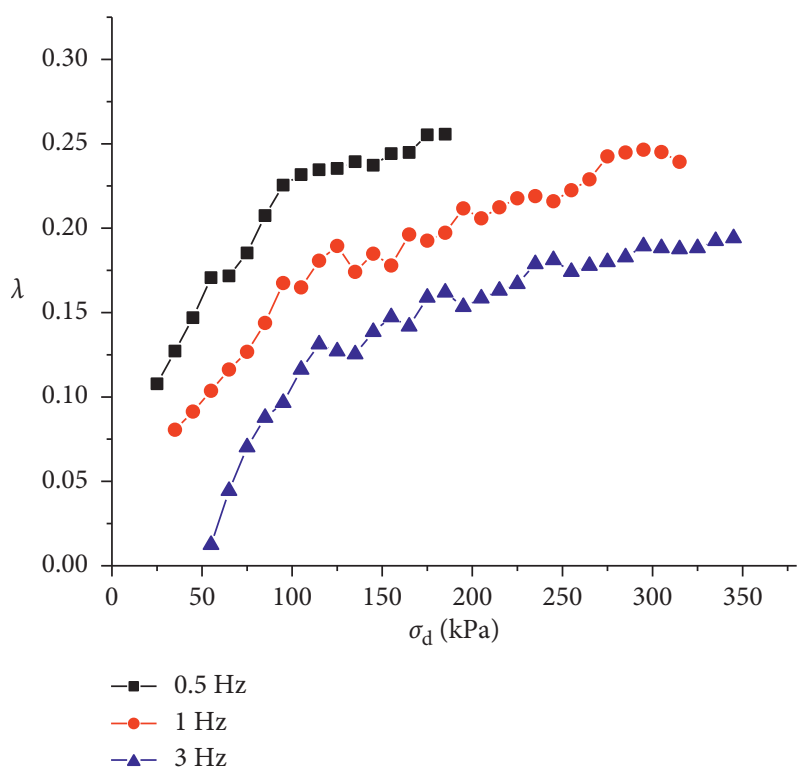

FIGURE 11: Damping ratio versus dynamic stress amplitude curves at different frequencies.

The variation in the damping ratio, $\lambda$, with cycle number $N$ at $1 \mathrm{~Hz}$ is shown in Figure 12. Under a small dynamic stress amplitude, the dynamic damping ratio of the sample decreased with the increase in the number of cycles. When the dynamic stress amplitude increased, the rate of decrease of the dynamic damping ratio began to decrease with the cycle number until the decrease rate reached zero. Subsequently, as the dynamic stress amplitude continued to increase, the dynamic damping ratio began to increase with the cycle number, and the rate of increase continued to increase.

\section{Establishment of Mudstone Dynamic Constitutive Model}

Based on the experimental results, an empirical dynamic constitutive model of mudstone that can describe the dynamic stress-strain expansion law of the sample in stable and damaged zones under cyclic loading was established.

Based on the hysteresis curve and Section 3.3, the dynamic elastic modulus was affected by cycle number $N$ and loading frequency $f$. In this study, the relationship between the dynamic stress and dynamic strain in the stable and failure zones was obtained, as expressed in the following equation:

$$
\varepsilon_{d}=\frac{\sigma_{d}}{E_{d}}
$$

To analyze the expression of the dynamic elastic modulus, a representative hysteresis curve was selected to fit the dynamic elastic modulus based on the test results. Figure 13 shows that the dynamic elastic modulus in the stable and failure zones changes with the cycle number under the loading frequencies of $0.5,1$, and $3 \mathrm{~Hz}$.

The fitting results showed that the dynamic elastic modulus in the stable zone increased with the increase in the cycle number, whereas the increase in the amplitude was gradually reduced. The dynamic elastic modulus in the failure zone decreased linearly with the increase in the cycle number. An empirical relationship between the dynamic elastic modulus and cycle number was obtained from the 


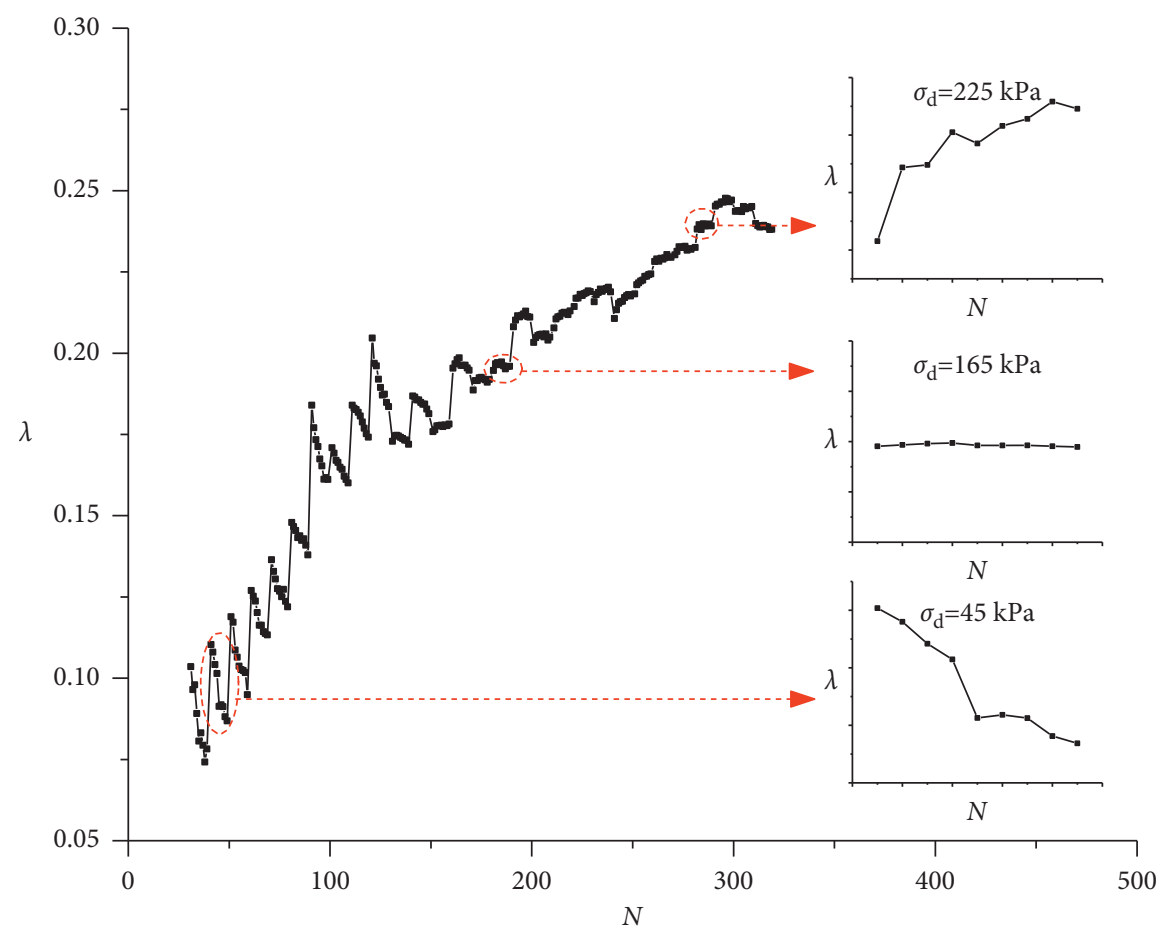

FIGURE 12: Damping ratio versus cycle number curves under different dynamic stress amplitudes.

fitting curve results. The stable and failure curves are expressed in the following equations, respectively.

$$
\begin{aligned}
& E_{d}=A_{1} \ln (N)+B_{1} \quad\left(A_{1}>0\right), \\
& E_{d}=A_{2} N+B_{2} \quad\left(A_{2}<0\right),
\end{aligned}
$$

where $A_{1}, A_{2}, B_{1}$, and $B_{2}$ denote the fitting parameters of the curve affected by the loading frequency.

To determine the functional relationship between the fitting parameters and loading frequency, the corresponding relationship curves were drawn, as depicted in Figure 14. As shown in Figure 14(a), fitting parameters $A_{1}$ and $B_{1}$ of the dynamic elastic modulus of the stable curve exhibited a linear relationship with the loading frequency, $f$, and the square of the correlation coefficient was above 0.9 (equations (9) and (10)).

$$
\begin{aligned}
& A_{1}=a_{1} f+b_{1}, \\
& B_{1}=a_{2} f+b_{2},
\end{aligned}
$$

where the values of fitting parameters $a_{1}, a_{2}, b_{1}$, and $b_{2}$ are $-0.8943,12.06,5.8381$, and 69.85 , respectively.

As depicted in Figure 14(b), fitting parameters $A_{2}$ and $B_{2}$ of the dynamic elastic modulus of the failure curve exhibited an exponential relationship with the loading frequency, $f$, and the square of the correlation coefficient was above 0.9 (equations (11) and (12)).

$$
\begin{aligned}
& A_{2}=l_{1} \exp \left(m_{1} f\right)+n_{1}, \\
& B_{2}=l_{2} \exp \left(m_{2} f\right)+n_{2},
\end{aligned}
$$

where the values of fitting parameters $l_{1}, l_{2}, m_{1}, m_{2}, n_{1}$, and $n_{2}$ are $-0.8686,19.12598,-2.5022,0.24154,-0.16752$, and 0 , respectively.

The aforementioned analysis can yield the relationship among the dynamic elastic modulus of the mudstone, cycle number, and load frequencies in the stable and failure zones.

The result of solving simultaneous equations (7), (9), and (10) is expressed in the following equation:

$$
E_{d}=\left(a_{1} f+b_{1}\right) \ln (N)+\left(a_{2} f+b_{2}\right) .
$$

The result of solving simultaneous equations (8), (11), and (12) is expressed in the following equation:

$$
E_{d}=\left[l_{1} \exp \left(m_{1} f\right)+n_{1}\right] N+\left[l_{2} \exp \left(m_{2} f\right)+n_{2}\right] .
$$

Using equations (6), (13), and (14), the dynamic constitutive models of the stable and failure zones of the mudstone under cyclic loading can be obtained.

Stable zone:

$$
\varepsilon_{d}=\frac{\sigma_{d}}{\left(a_{1} f+b_{1}\right) \ln (N)+\left(a_{2} f+b_{2}\right)} .
$$

Failure zone:

$$
\varepsilon_{d}=\frac{\sigma_{d}}{\left[l_{1} \exp \left(m_{1} f\right)+n_{1}\right] N+\left[l_{2} \exp \left(m_{2} f\right)+n_{2}\right]} .
$$

In a constructed model, the unstable input parameters may result in the uncertainty of the model outputs. VuBac et al. [24] provided a robust and powerful modeling tool to quantify the influence of uncertain input parameters on uncertain model outputs. In this study, the 


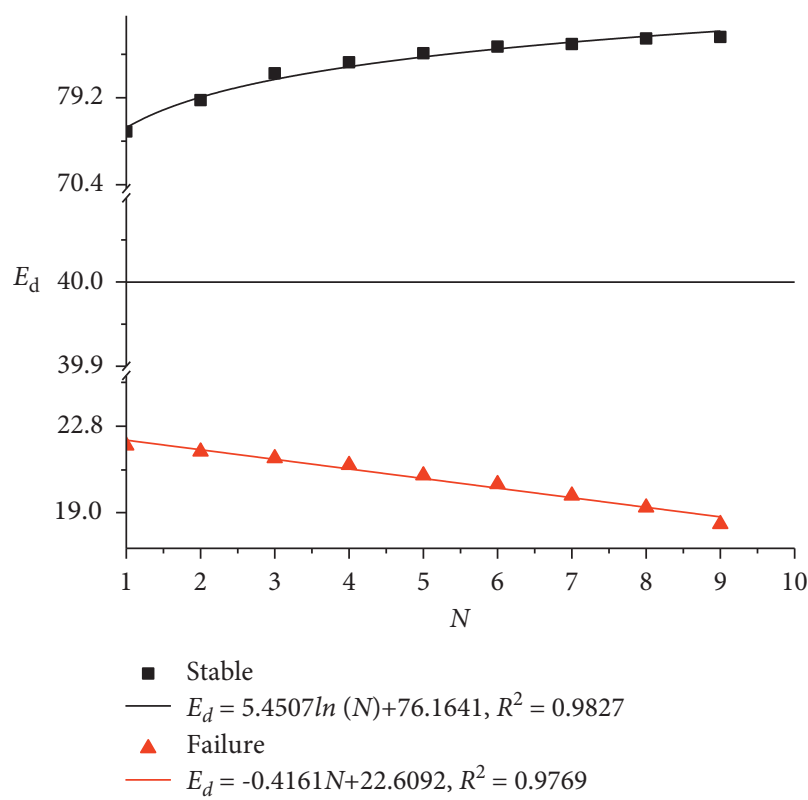

(a)

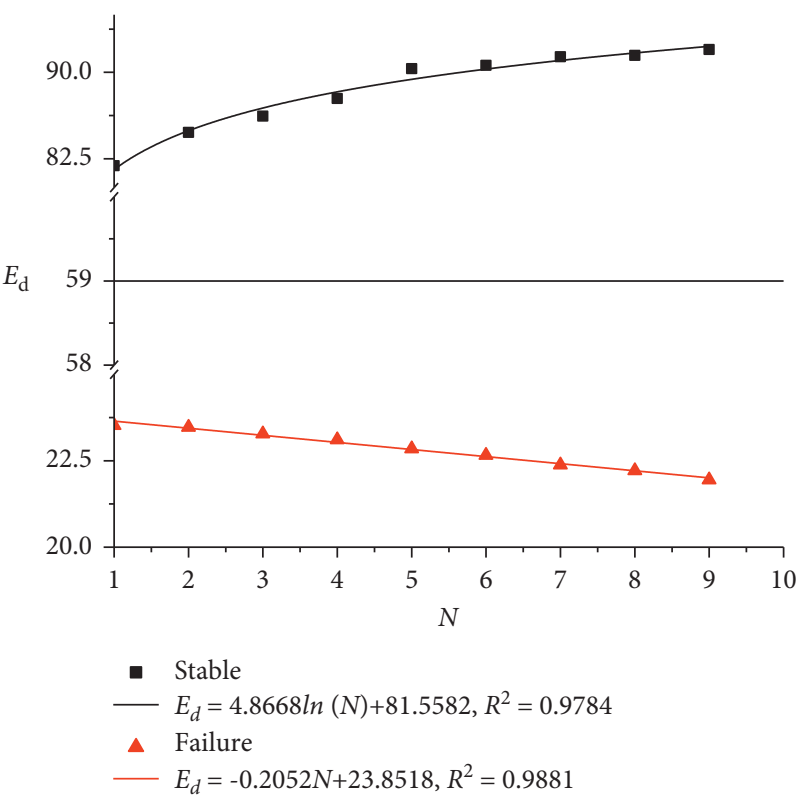

(b)

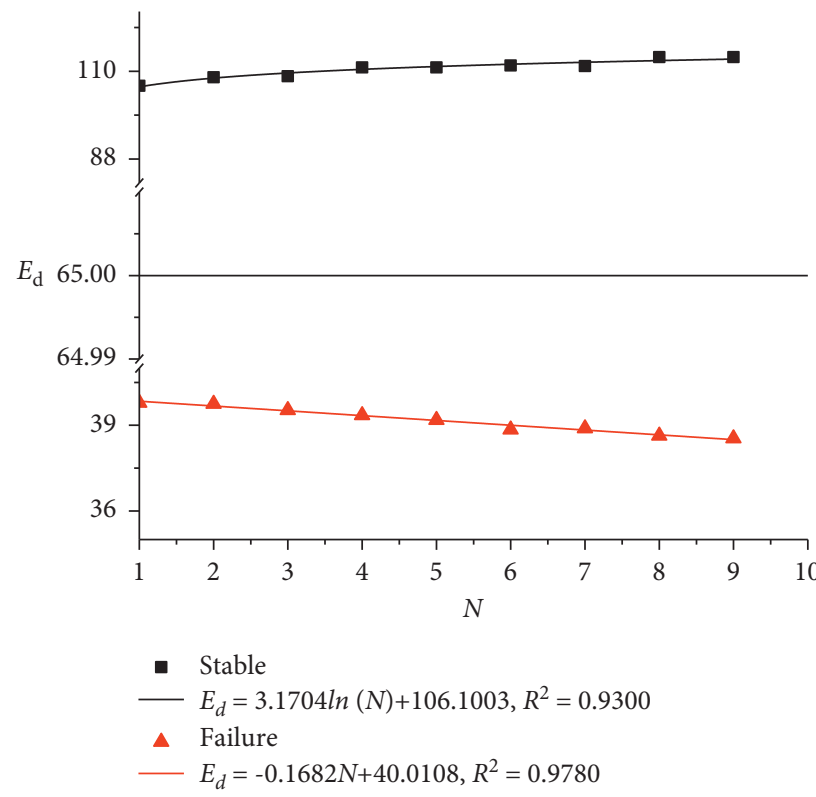

(c)

Figure 13: Dynamic elastic modulus versus cycle number curves in stable and failure zones. (a) $0.5 \mathrm{~Hz}$. (b) $1 \mathrm{~Hz}$. (c) $3 \mathrm{~Hz}$.

sensitivity analysis method was used to consider the uncertainties. The results indicated that the dynamic stress amplitude, $\sigma_{d}$, was the most important parameter followed by the frequency, $f$, and cycle number, $N$. The other parameters related to the physical and mechanical properties of the samples exhibited insignificant influences on the axial strain.

\section{Discussion}

(1) Based on the results of the conducted dynamic triaxial tests, the critical dynamic stress ranges of the sliding zone mudstone under $0.5,1$, and $3 \mathrm{~Hz}$ frequencies are
$125-145,235-255$, and $245-285 \mathrm{kPa}$, respectively. The average critical dynamic stress of the mudstone in the sliding zone increases with the increase in frequency. This indicated that increasing the frequency can enhance the antidynamic ability of the sliding zone and improve the stability of landslides.

(2) Based on the dynamic elastic modulus, a dynamic constitutive model was established in this study. The model can be employed to describe the dynamic stress-strain relationships of the samples under cyclic loading. Under a certain dynamic stress amplitude, the dynamic stress-strain relationship expressed by the model can be transformed into the relationship 


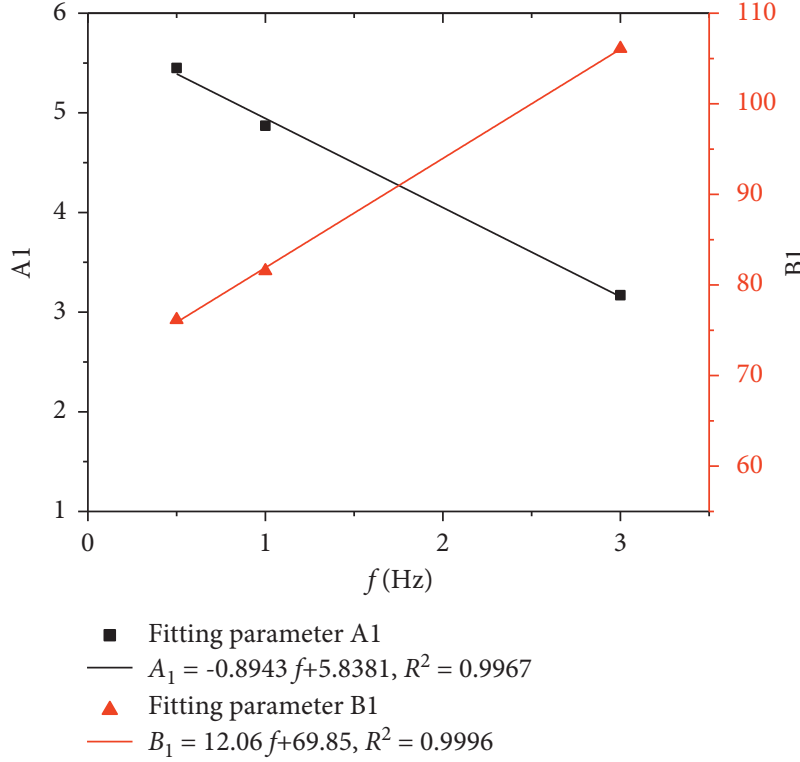

(a)

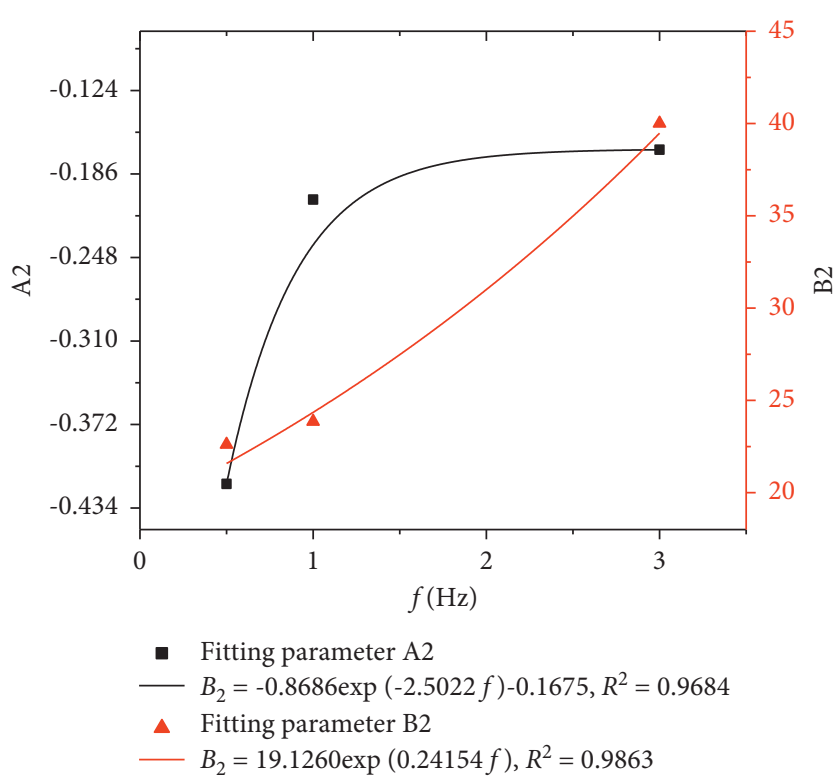

(b)

FIGURE 14: Curves of fitting parameters of dynamic elastic modulus versus frequency. (a) Stable curve-fitting parameters. (b) Failure curvefitting parameters.

between the number of cyclic vibrations and dynamic strain. When the dynamic stress is set as a variable, equation (15) can be transformed for studying the dynamic strength of the mudstone in the slip zone under a cyclic dynamic load. This model is suitable for a test case in which the axial dynamic load increases stepwise, instead of continuously increasing axial dynamic load.

(3) The experimental study is based on a high-steep rock landslide with a weak interlayer in the Qinling-Daba mountain, and the results provide a basis for the dynamic study of landslides in this area. In this study, the dynamic characteristics test is conducted on the weak layer of rock landslide. The deformation characteristics of landslide weak interlayer under dynamic action are analyzed, and relevant conclusions are obtained. However, the case of the soft and hard interlayer contact surfaces is not involved in this study. More research is needed to conduct on the influence of dynamic load from the perspective of soft and hard interlayer contact surfaces and dynamic intermittent loading.

\section{Conclusions}

(1) The dynamic stress amplitude and loading frequency presented a significant effect on the deformation characteristics of the mudstone samples in the sliding zone of the Shanyang landslide. The axial strain increased with the increase in the cycle number, and the rate of increase continuously increased. Increasing the dynamic stress amplitude and cycle number increased the elastic and plastic strains exponentially.
Additionally, the elastic strain was more sensitive to the increase in the dynamic stress amplitude compared to the plastic strain. As the loading frequency increased, the number of cycles required for the failure of the specimen increased, the strain decreased, and the strain growth rate decreased. Additionally, the influence of the loading frequency on the strain decreased with the increase in the loading frequency.

(2) The dynamic elastic modulus decreased linearly with the increase in the dynamic stress amplitude, and as the frequency decreased, the linear decrease rate of the dynamic elastic modulus increased. The damping ratio increased with the increase in the dynamic stress amplitude. Under the same dynamic stress amplitude, as the loading frequency increased, the dynamic elastic modulus increased and the damping ratio decreased.

(3) In the dynamic stress-strain relationship, the dynamic elastic modulus in the stable zone increased with the increase in the cycle number, whereas that in the failure zone decreased with the increase in the cycle number. The empirical model of the dynamic constitutive relationship with cycle number $N$ and loading frequency $f$ based on the dynamic elastic modulus could satisfactorily describe the dynamic stress-strain relationship of the samples in the stable and failure zones.

\section{Data Availability}

The experimental data used to support the findings of this study are included in the article. 


\section{Conflicts of Interest}

The authors declare no conflicts of interest regarding the publication of this study.

\section{Acknowledgments}

This study was funded by the National Natural Science Foundation of China (Grant no. 41977228).

\section{References}

[1] R. Huang and W. Li, "Formation, distribution and risk control of landslides in China," Journal of Rock Mechanics and Geotechnical Engineering, vol. 3, no. 2, pp. 97-116, 2011.

[2] J. J. Zhou, X. M. Zhang, F. S. Zhao, and H. Li, "Research on risk assessment of geological hazards in Qingling-Daba mountain area, south Shaanxi province," Journal of Geomechanics, vol. 25, no. 4, pp. 544-553, 2019.

[3] B. Wen, S. Wang, E. Wang, and J. Zhang, "Characteristics of rapid giant landslides in China," Landslides, vol. 1, no. 4, pp. 247-261, 2004.

[4] D. G. Duan and L. Xu, "Countermeasures for urban and rural construction in the Qinba Mountain area after 5.12 Earthquake," Journal of Xi'an University of Architecture and Technology, vol. 5, pp. 720-726, 2008.

[5] S. H. Cui, Q. w. Yang, X. J. Pei, R. Q. Huang, B. Guo, and W. F. Zhang, "Geological and morphological study of the Daguangbao landslide triggered by the Ms. 8.0 Wenchuan earthquake, China," Geomorphology, vol. 370, Article ID 107394, 2020.

[6] Y. Yin, P. Sun, M. Zhang, and B. Li, "Mechanism on apparent dip sliding of oblique inclined bedding rockslide at Jiweishan, Chongqing, China," Landslides, vol. 8, no. 1, pp. 49-65, 2011.

[7] Y. Q. Xu, "The 8.12 landslide in Shanyang county, Shaanxi province," Chinese Journal of Geological Hazard and Control, vol. 26, no. 3, p. 25, 2015.

[8] G. j. Zhao, Y. Huan, Y. Yan et al., "Experimental study on the dynamic properties of lime-solidified soft soil under cyclic loading," Arabian Journal of Geosciences, vol. 13, no. 14, 2020.

[9] D. Zhang, Q. M. Li, E. L. Liu et al., "Dynamic properties of frozen silty soils with different coarse-grained contents subjected to cyclic triaxial loading," Cold Regions Science and Technology, vol. 157, 2018.

[10] Y. D. Sun, Y. Yang, and M. Li, "Dynamic behavior and fatigue damage evolution of sandstone under uniaxial cyclic loading," Shock and Vibration, vol. 2020, Article ID 1452159, 9 pages, 2020.

[11] G. D. Jiao, S. P. Zhao, W. Ma, and X. B. Kong, "Evolution laws of hysteresis loops of frozen soil under cyclic loading," Chinese Journal of Geotechnical Engineering, vol. 35, no. 7, pp. 1343-1349, 2013.

[12] A. K. Anupam, P. Kumar, and R. N. G. D. Ransinchung, "Effect of fly ash and rice husk ash on permanent deformation behaviour of subgrade soil under cyclic triaxial loading," Transportation Research Procedia, vol. 17, pp. 596-606, 2016.

[13] R. Mu, Z. H. Huang, S. Y. Pu et al., "Accumulated deformation characteristics of undisturbed red clay under cyclic loading and dynamic constitutive relationship," Rock and Soil Mechanics, vol. S2, pp. 1-10, 2020.

[14] T. Wichtmann, A. Niemunis, and T. Triantafyllidis, "Strain accumulation in sand due to cyclic loading: drained cyclic tests with triaxial extension," Soil Dynamics and Earthquake Engineering, vol. 27, no. 1, pp. 42-48, 2007.
[15] M. Touqan, A. Ahmed, H. El Naggar, and T. Stark, "Static and cyclic characterization of fouled railroad sub-ballast layer behaviour," Soil Dynamics and Earthquake Engineering, vol. 137, Article ID 106293, 2020.

[16] X. S. Zhuang, H. W. Zhao, J. X. Wang, and Y. J. Huang, "Experimental study of dynamic elastic modulus and damping ratio of expansive soil in Hefei," Journal of Zhejiang University (Engineering Science), vol. 54, no. 4, pp. 759-766, 2020.

[17] X. S. Zhuang and C. H. Peng, "Experimental study on mechanical properties of expansive soil under dynamic load," Journal of Yangtze University (Natural Science Edition), vol. 18, no. 1, 2021.

[18] R. S. Nie, Y. F. Li, W. M. Leng et al., "Plastic deformation behaviour and critical dynamic stress of fine-grained soil under intermittent loading of trains," Chinese Journal of Rock Mechanics and Engineering, vol. 40, no. 4, pp. 828-841, 2021.

[19] R. Yoshinaka, T. V. Tran, and M. Osada, "Mechanical behavior of soft rocks under triaxial cyclic loading conditions," International Journal of Rock Mechanics and Mining Sciences, vol. 34, no. 3-4, p. 690, 1997.

[20] Z. L. Zhang, S. R. Wu, H. M. Tang, T. Wang, and P. Xin, "Dynamic characteristics and microcosmic damage effect of loess and mudstone," Chinese Journal of Rock Mechanics and Engineering, vol. 36, no. 5, pp. 1256-1268, 2017.

[21] Z. L. Zhang, T. Wang, S. R. Wu, H. Tang, P. Xin, and C. Liang, "Dynamics stress-strain behavior of Tianshui soils," Landslides, vol. 14, 2017.

[22] T. Rabczuk and T. Belytschko, "Cracking particles: a simplified meshfree method for arbitrary evolving cracks," International Journal for Numerical Methods in Engineering, vol. 61, no. 13, pp. 2316-2343, 2004.

[23] H. Ren, X. Zhuang, and T. Rabczuk, "Dual-horizon peridynamics: a stable solution to varying horizons," Computer Methods in Applied Mechanics and Engineering, vol. 318, pp. 762-782, 2017.

[24] N. Vu-Bac, T. Lahmer, X. Zhuang, T. Nguyen-Thoi, and T. Rabczuk, "A software framework for probabilistic sensitivity analysis for computationally expensive models," Advances in Engineering Software, vol. 100, pp. 19-31, 2016.

[25] C. Q. Zhu, Y. Huang, and J. Sun, "Solid-like and liquid-like granular flows on inclined surfaces under vibration - implications for earthquake-induced landslides," Computers and Geotechnics, vol. 123, Article ID 103598, 2020.

[26] L. Zhu, X. J. Pei, S. H. Cui, S. Wang, X. Zhang, and L. Yufei, "On the initiation mechanism of the Daguangbao landslide triggered by the 2008 Wenchuan (Ms 7.9) earthquake," Soil Dynamics and Earthquake Engineering, vol. 137, Article ID 106272, 2020.

[27] L. Zhu, X. J. Pei, S. H. Cui, and X. Meng, "Triaxial tests for dynamic characteristics of the bedding fault material within basal layer of Daguangbao landslide," Journal of Engineering Geology, vol. 26, no. 3, pp. 647-654, 2018.

[28] W.-j. Xu, Y.-x. Jie, Q.-b. Li, X.-b. Wang, and Y.-Z. Yu, "Genesis, mechanism, and stability of the Dongmiaojia landslide, yellow river, China," International Journal of Rock Mechanics and Mining Sciences, vol. 67, no. 2, pp. 57-68, 2014.

[29] B. H. Song, W. W. Chen, W. J. Wu, and Y. Jiang, "Experimental study on the dynamic properties of sliding zone soil of a landslide under varying water content," China Earthquake Engineering Journal, vol. 39, no. 4, pp. 744-749, 2017.

[30] Standardization Administration of China (SAC), Ministry of Construction, Ministry of Water Resources, "Chinese National 
Specification (Standard for Geotechnical Testing Method, GB/T 50123-2019), China Planning Press, Beijing, China, 2019.

[31] Y. Cai and X. W. Cao, "Preliminary study on the critical dynamic stress and permanent deformation of subgrade filling under repeated loading," Journal of Southwest Jiaotong University, vol. 31, no. 1, pp. 1-5, 1996.

[32] H. E. Stewart, "Permanent strains from cyclic variable-amplitude loadings," Journal of Geotechnical Engineering, vol. 112, no. 6, pp. 646-660, 1986.

[33] Y. Zhou, Experimental Study on Dynamic Characteristics of Saturated Silty clay under Cyclic Loading, Southwest Jiaotong University, Chengdu, China, 2014.

[34] G. H. Minassian, Behavior of Granular Materials under Cyclic and Repeated Loading, University of Alaska Fairbanks, Fairbanks, AK, US, 2003.

[35] D. Y. Xie, Soil Dynamics, Higher Education Press, Beijing, China, 2011. 